\title{
Fibras de polipropileno e sua influência no comportamento de concretos expostos a altas temperaturas. Revisão
}

\section{(Polypropylene fibers and their influence on the behavior of concretes exposed to high temperatures. Review)}

\author{
A. L. de Castro, P. R. T. Tiba, V. C. Pandolfelli \\ Grupo de Engenharia de Microestrutura de Materiais (GEMM), Departamento de Engenharia de Materiais, \\ Universidade Federal de S. Carlos, Rod. Washington Luiz, km 235, S. Carlos, SP 13565-905 \\ alelorencastro@yahoo.com.br,tiba_em03@yahoo.com.br,vicpando@power.ufscar.br
}

\begin{abstract}
Resumo
A resistência ao fogo de um elemento estrutural de concreto é avaliada pelo intervalo de tempo em que o elemento continua a desempenhar suas funções sob condições de alta temperatura. Normalmente acredita-se que o concreto tem uma excelente durabilidade frente à ação do fogo, entretanto, na prática, a estabilidade desse material é prejudicada pelas altas temperaturas e os elementos de concreto têm apresentado danos excessivos ou mesmo rupturas catastróficas sob tais condições. Quando expostos às altas temperaturas, materiais à base de cimento sofrem mudanças físico-químicas que prejudicam suas propriedades mecânicas e comprometem sua resistência à transferência de calor. Embora as características térmicas de um concreto de alta resistência sejam semelhantes aos de um concreto convencional, este material possui uma maior sensibilidade às altas temperaturas devido à sua porosidade reduzida, apresentando uma maior perda relativa das propriedades mecânicas e a ocorrência do lascamento explosivo na faixa de temperatura entre $100{ }^{\circ} \mathrm{C}$ e $400{ }^{\circ} \mathrm{C}$. O lascamento pode ser evitado pela introdução de fibras de polipropileno na composição do concreto: quando fundidas e parcialmente absorvidas pela matriz de cimento, as fibras criam uma rede de canais permeável que permite a migração dos gases para o exterior, reduzindo a pressão nos poros do material e, conseqüentemente, eliminando a possibilidade de ocorrência do lascamento explosivo. Assim, no presente artigo, uma revisão sobre o comportamento de concretos expostos às altas temperaturas, bem como a influência da fibra de polipropileno sobre este comportamento foi realizada, direcionando-se para os concretos aplicados na construção civil.

Palavras-chave: concreto, fibras de polipropileno, resistência mecânica, lascamento.
\end{abstract}

\begin{abstract}
The fire resistance of a structural concrete is evaluated by the time length that the element keeps performing its functions under high temperature conditions. It is usually believed that the concrete has an excellent durability before fire; however, in practice the stability of this material is reduced by high temperatures. Unfortunately, under such circumstances, concrete elements present excessive damages or even catastrophic failures. When exposed to high temperatures, cement based materials undergo physicochemical changes that damage their mechanical properties and spoil their resistance to heat transfer. Although the thermal features of a high strength concrete are similar to those of a conventional concrete, this material has a greater sensibility to high temperatures due to its reduced porosity, showing a higher relative loss of the mechanical properties and explosive spalling in the temperature range between $100{ }^{\circ} \mathrm{C}$ and $400{ }^{\circ} \mathrm{C}$. The spalling can be avoided by adding polypropylene fibers in concrete: when melted and partially absorbed by the cement matrix, the fibers generate a permeable network that allows the outward gas migration, decreasing the pore pressure in the material and, consequently, eliminating the possibility of explosive spalling occurrence. Thus, in the present paper, a review regarding the behavior of concretes exposed to high temperatures, as well as the influence of polypropylene fibers have been addressed for concretes applied in the civil engineering area.
\end{abstract}

Keywords: concrete, polypropylene fibers, mechanical resistance, spalling.

\section{INTRODUÇÃO}

Quando utilizados nas construções, os elementos estruturais de concreto devem ser projetados para atender tanto aos requisitos de solicitações mecânicas quanto aos de resistência ao fogo. Este último aspecto é avaliado pelo intervalo de tempo em que o elemento estrutural continua a desempenhar suas funções sob condições de alta temperatura. Isto implica que a resistência ao fogo está relacionada com o próprio elemento estrutural e não com o material que o constitui, porém é imprescindível que o desempenho do material não comprometa a resistência do elemento [1]. Um dos fatores determinantes do comportamento de um elemento estrutural de concreto frente à ação do fogo é a sua capacidade de isolar o calor (impedindo que ele atinja a armadura) e de suportar a subseqüente ação da água e do resfriamento mantendo suas propriedades mecânicas. Assim, os requisitos de resistência ao fogo podem ser atribuídos ao 
fato de que, quando falharem as outras medidas de controle do fogo, a integridade estrutural é a última defesa do elemento de concreto. Geralmente acredita-se que o concreto tem uma excelente durabilidade frente à ação do fogo, sendo considerado um escudo efetivo para a armadura. Entretanto, na prática, observa-se que o fogo prejudica o desempenho do material e os elementos de concreto apresentam danos excessivos ou mesmo rupturas catastróficas após serem expostos a altas temperaturas, particularmente os concretos de alta resistência [2-4]. Quando o concreto é submetido a altas temperaturas, as distintas propriedades térmicas de seus constituintes promovem a fissuração. Adicionalmente, tensões internas são geradas devido à mudança da microestrutura decorrente da decomposição das fases hidratadas e ao desenvolvimento de altas pressões de vapor nos poros. Com isso, o material passa por uma série de transformações e reações que resultam na progressiva quebra da estrutura de gel do C-S-H e, conseqüentemente, perda da capacidade portante do elemento estrutural (redução da resistência mecânica), aumento da tendência à retração por secagem, fissuração, lascamento, mudança de coloração associada com o agregado e mudança na estrutura de poros (crescimento dos poros) levando ao aumento da permeabilidade e à redução da durabilidade [5-8]. Assim, a simulação das condições de exposição às altas temperaturas - tais como aquelas geralmente experimentadas durante um incêndio acidental - são de grande importância para a avaliação do comportamento de elementos estruturais de concreto. $\mathrm{O}$ desempenho do concreto deve ser avaliado de acordo com sua capacidade de atuar como uma barreira térmica, sua estabilidade volumétrica e suas propriedades mecânicas, atendendo a rigorosos requisitos de normas com relação à segurança ao fogo. O comportamento de concretos expostos às altas temperaturas ou à ação do fogo é determinado pela matriz de cimento, agregado, teor de umidade, estrutura de poros e carregamento aplicado, além da temperatura máxima, tempo de exposição e taxas de aquecimento e resfriamento $[1,7,9]$.

\section{Comportamento do concreto exposto a altas temperaturas}

O efeito das altas temperaturas sobre as propriedades mecânicas do concreto tem sido investigado desde 1940 e, desde então, tem-se constatado sua influência sobre o comportamento destes materiais. Quando expostos às altas temperaturas, materiais à base de cimento sofrem mudanças físico-químicas que prejudicam suas propriedades mecânicas e comprometem sua resistência à transferência de calor [1]. Assim, para predeterminar a resposta de estruturas de concreto durante e após a exposição em elevadas temperaturas é essencial que as propriedades microestruturais deste material sejam totalmente compreendidas [10]. A estrutura do concreto pode ser dividida em aproximadamente três níveis - micro $(<1 \mu \mathrm{m})$, meso (entre $1 \mu \mathrm{m}$ e $1 \mathrm{~cm})$ e macro $(>1 \mathrm{~cm})$ - sendo que a temperatura influencia o seu comportamento nos diferentes níveis estruturais. Nos níveis micro e meso, o concreto sofre tanto mudanças físicas quanto químicas. Fisicamente, as dilatações e as retrações térmicas promovem uma grande mudança de volume que resulta em altas tensões e deformações internas, levando à microfissuração e, conseqüentemente, à redução da resistência mecânica do material. Adicionalmente, a estrutura de poros (porosidade, tamanho e distribuição dos poros) é alterada, gradientes térmicos e hídricos são formados permitindo a migração da água (difusão e secagem) e, no caso particular dos concretos de alta resistência, ocorre o desenvolvimento de altas pressões nos poros, levando ao lascamento explosivo de material. Quimicamente, as altas temperaturas aumentam a desidratação e promovem a decomposição da pasta de cimento endurecida e dos agregados. No nível macro, em função das alterações observadas nos níveis anteriores, a resistência, a dureza e a tenacidade - propriedades fundamentais para o comportamento do concreto na ruptura - são reduzidas e o material passa por deformações irreversíveis, aumentando o dano na estrutura. Desta forma, o estudo da estrutura de poros no concreto após a exposição às altas temperaturas ajuda a compreender os mecanismos de deterioração deste material $[11,12]$. Portanto, quando um material à base de cimento como o concreto é aquecido, diversos fenômenos químicos e físicos ocorrem na faixa de temperatura entre $100{ }^{\circ} \mathrm{C}$ e 900 ${ }^{\circ} \mathrm{C}$. Até aproximadamente $550{ }^{\circ} \mathrm{C}$, apenas a pasta de cimento passa por mudanças físicas e químicas, enquanto a maioria dos agregados comumente utilizados é pouco influenciada pelo aquecimento. Nesta faixa de temperatura, as reações endotérmicas ocorrem seguindo a ordem: liberação da água da pasta de cimento (água capilar), desidratação da etringita, do monossulfoaluminato de cálcio e do silicato de cálcio hidratado (C-S-H), decomposição do hidróxido de cálcio $\left(\mathrm{Ca}(\mathrm{OH})_{2}\right)$, do C-S-H e do carbonato de cálcio. Com relação aos agregados, os efeitos das altas temperaturas sobre o agregado de sílica são distintos daqueles sobre os calcários: na temperatura ambiente, a forma estável do quartzo é a forma $\alpha$, que se transforma em $\beta$-quartzo a $573{ }^{\circ} \mathrm{C}$, que posteriormente se transforma em $\beta$-tridimita a $867{ }^{\circ} \mathrm{C}$ e que, para temperaturas superiores a $900{ }^{\circ} \mathrm{C}$, se transforma em $\beta$-cristobalita; por outro lado, os agregados calcários apenas se dissociam para temperaturas variando entre $700{ }^{\circ} \mathrm{C}$ e $970{ }^{\circ} \mathrm{C}$ $[1,10]$. Assim, o comportamento de concretos expostos às altas temperaturas não pode ser relacionado com um fator único, sendo na verdade influenciado por diversos aspectos, tais como a taxa de aquecimento, a temperatura máxima de exposição, a relação água/cimento, o tipo de agregado, o teor de umidade, a porosidade, a resistência do concreto, o tamanho e a idade da amostra, o tipo de cura, a adição mineral e/ou o tipo de fibra incorporada, o carregamento aplicado etc., de maneira que a alta temperatura influencia o seu comportamento tensão-deformação e a transferência de umidade e calor no seu interior $[1,5,10,11,13]$.

Embora os parâmetros térmicos-como o calor específico, a difusividade, a condutividade térmica e o coeficiente de expansão térmica - de um concreto de alta resistência sejam semelhantes aos de um concreto convencional, estes materiais apresentam uma maior sensibilidade às altas 
temperaturas devido à sua porosidade reduzida, composta por poros pequenos e pouco interconectados [13-15]. A temperatura de $100{ }^{\circ} \mathrm{C}$ é um limite importante, pois acima dela a permeabilidade do concreto aumenta em duas ordens de grandeza devido ao aumento do tamanho dos poros associado com a vaporização da água adsorvida e pela desidratação das fases hidratadas [16]. As duas diferenças principais observadas entre os comportamentos dos concretos de alta resistência e dos concretos convencionais expostos às altas temperaturas são a perda relativa das propriedades mecânicas (resistência à compressão e módulo de elasticidade) e a ocorrência do lascamento explosivo (mesmo para taxas de aquecimento relativamente baixas, ou seja, $\leq 5^{\circ} \mathrm{C} / \mathrm{min}$ ) na faixa de temperatura entre $100{ }^{\circ} \mathrm{C}$ e 400 ${ }^{\circ} \mathrm{C}$ [17-19]. Com isso, surgem dúvidas sobre a aplicabilidade das normas existentes para o projeto de estruturas de concretos de alta resistência expostas à ação do fogo, uma vez que elas são amplamente baseadas no comportamento de concretos convencionais. Além disso, o mecanismo de ruptura pelo lascamento explosivo tem sido observado de maneira inconsistente nesses materiais. Geralmente, o lascamento ocorre em algumas poucas amostras de um grupo amplo de corpos, todos submetidos a condições de ensaio idênticas. Esse comportamento irregular dificulta predeterminar com precisão se um determinado concreto de alta resistência romperá por lascamento explosivo quando exposto ao fogo; porém, acredita-se que ele ocorre para certas combinações de ensaio e que concretos com a adição de sílica ativa (mais densos) sejam mais susceptíveis ao lascamento [14, 17, 19-21].

Os resultados de ensaios com concretos convencionais mostram que o comportamento sob compressão mecânica é bastante influenciado pela temperatura, em ambas as condições transitórias e estacionárias. Dentre os fatores que influenciam a forma da curva tensão-deformação, a razão agregado/cimento, o tipo de agregadoe as condições de ensaio são citados. Além disso, sendo as propriedades mecânicas residuais o parâmetro avaliado (após o resfriamento), outros fatores também devem ser considerados, tais como a taxa de resfriamento, o tipo de aglomerante e as condições de armazenagem [16]. As mesmas condições se aplicam aos concretos de alta resistência, porém estes materiais perdem sua resistência à compressão e sua dureza mais rapidamente devido à maior densidade da pasta de cimento, à redistribuição de tensões promovida pelo enfraquecimento da argamassa e dano aos agregados que se tornam sobrecarregados e à maior sensibilidade às microfissuras induzidas termicamente [16].

Com relação ao efeito sobre a perda de resistência dos concretos, as altas temperaturas podem ser divididas em três faixas, isto é, entre $20^{\circ} \mathrm{C}$ e $400{ }^{\circ} \mathrm{C}$, entre $400{ }^{\circ} \mathrm{C}$ e $800{ }^{\circ} \mathrm{C}$ e acima de $800{ }^{\circ} \mathrm{C}$. Na faixa entre $20^{\circ} \mathrm{Ce} 400{ }^{\circ} \mathrm{C}$, o concreto de alta resistência sofre maiores perdas de resistência do que o concreto convencional. Na faixa entre $400{ }^{\circ} \mathrm{Ce} 800{ }^{\circ} \mathrm{C}$, apesar da diminuição da diferença da taxa de perda de resistência entre os concretos convencional e o de alta resistência, ambos perdem a maior parte de sua resistência original, especialmente para temperaturas acima de $600{ }^{\circ} \mathrm{C}$. É nesta faixa de temperatura que ocorre a indesejável desidratação do gel de C-S-H da pasta de cimento, considerada crítica em termos de perda da resistência. Acima de $800{ }^{\circ} \mathrm{C}$, apenas uma pequena porção (aproximadamente 30\%) da resistência original é mantida para ambos os concretos [2, 5, 17].

No estudo [6] para amostras de concreto expostas a diferentes regimes de temperatura durante um intervalo de tempo específico, o efeito da temperatura sobre a resistência à compressão do material foi praticamente desprezível até $400{ }^{\circ} \mathrm{C}$; porém, devido a perda da água de ligação, verificouse uma perda significativa da resistência à compressão para temperaturas superiores, resultando tanto na redução do teor de $\mathrm{Ca}(\mathrm{OH})_{2}$ quanto em mudanças da morfologia dos hidratos e na formação de microfissuras. Assim, a perda de resistência observada com o aumento da temperatura pode estar relacionada com a perda da água de ligação, com o aumento da porosidade e, conseqüentemente, com o aumento da permeabilidade, tornando o concreto cada vez mais susceptível à destruição. De acordo com os experimentos desenvolvidos [3], verifica-se uma relação entre a resistência à compressão residual e a permeabilidade do concreto, sendo que quanto mais permeável for a amostra, mais pronunciada será a perda de resistência. Os concretos de alta resistência, principalmente os incorporados com sílica ativa, que possuem baixa permeabilidade a temperatura ambiente, quando expostos às altas temperaturas, apresentam um aumento significativo da permeabilidade: após a ação do fogo, tais concretos podem ser considerados não-duráveis dependendo da situação, mesmo que uma grande parte de sua resistência à compressão seja mantida. $\mathrm{O}$ aumento da porosidade e do diâmetro médio dos poros com o aumento da temperatura pode ser considerado como o responsável pela perda de resistência e aumento da permeabilidade dos concretos. Assim, mesmo que o concreto conserve boa parte de sua resistência mecânica, a avaliação quanto a sua durabilidade deve ser feita, já que a perda desta propriedade pode resultar na deterioração do concreto e da armadura, reduzindo a vida útil da estrutura. No caso da resistência à tração por compressão diametral, verifica-se que o comportamento de concretos expostos às altas temperaturas é bastante distinto da perda gradual normalmente observada para a resistência à compressão. Isto porque uma elevada quantidade de microe macro-fissuras são produzidas nas amostras em função das incompatibilidades térmicas existentes no interior do concreto, bem como da decomposição do $\mathrm{Ca}(\mathrm{OH})_{2}$ e de outros hidratados e/ou componentes. Dessa maneira, a resistência à tração dos concretos é mais sensível à formação de fissuras do que a sua resistência à compressão $[2,5,13$, 22]. À medida que a temperatura aumenta, a resistência à compressão diminui e a deformação de pico aumenta; em outras palavras, o concreto enfraquece. Assim, o módulo de elasticidade diminui com o aumento da temperatura e, para um mesmo tratamento térmico, a redução no módulo é maior do que a da resistência à compressão. Como observado na Fig. 1, a forma da curva tensão-deformação varia com a temperatura. Além disso, a ruptura da pasta de cimento tende a coincidir com a ruptura dos agregados; como resultado, a 
parte pós-pico da curva é mais íngreme nesses concretos do que nos concretos convencionais e a ductilidade induzida termicamente é mais pronunciada $[8,16]$.

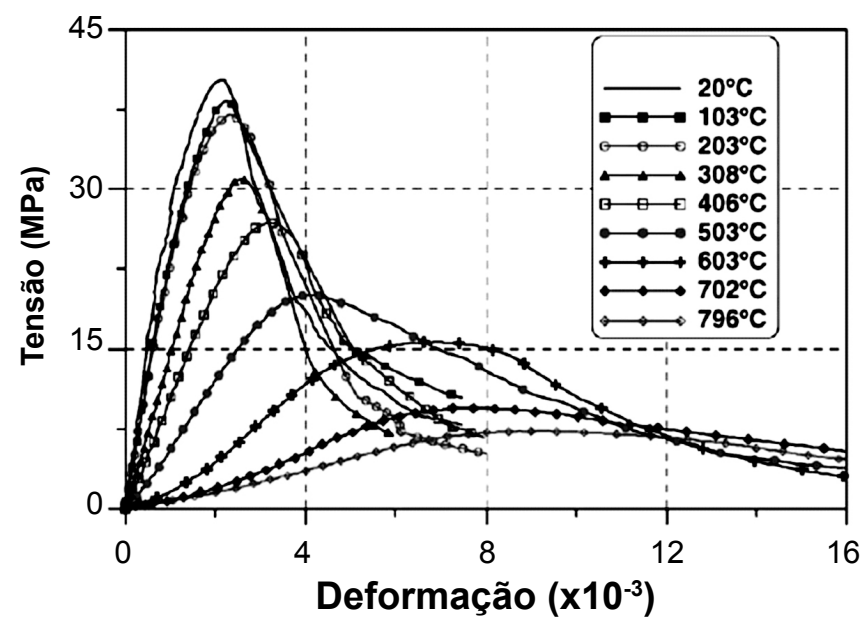

Figura 1: Curvas tensão-deformação de um concreto após aquecimento a diferentes temperaturas [8].

[Figure 1: Stress-strain curves of concretes after heating at different temperatures [8].]

No caso da tenacidade dos concretos, para menores temperaturas de aquecimento (até $300{ }^{\circ} \mathrm{C}$ ), a temperatura relativamente alta no interior do concreto favorece uma hidratação adicional da pasta de cimento e fortalece a zona de interface. Porém, um aquecimento adicional promove uma microfissuração mais severa, a desidratação e a decomposição dos hidratos, reduzindo a resistência à fissuração [12]. Para maiores temperaturas de exposição (acima de $300{ }^{\circ} \mathrm{C}$ ), dois fenômenos podem ocorrer: perda de umidade e mudanças microestruturais que, em conjunto, geram microfissuras na interface entre a pasta de cimento e os agregados e na própria pasta de cimento e nos agregados, reduzindo a tenacidade do concreto [23]. De uma forma geral, a resistência, a dureza e a tenacidade do concreto diminuem com o aumento da temperatura, tempo de exposição e ciclos térmicos. Dessa maneira, o concreto se torna mais frágil. Portanto, as mudanças nas propriedades mecânicas dos concretos sob altas temperaturas estão relacionadas com a evaporação da umidade do concreto, física ou quimicamente. A presença de água permite que estas propriedades se desenvolvam com o tempo por meio da relação água/cimento e do grau de hidratação. De acordo com o tamanho dos poros que ela preenche, a água presente no concreto pode ser classificada como água capilar, água de gel e água quimicamente combinada. A água capilar é a água que evapora rapidamente e existe tanto nos poros capilares ( $100 \AA-2000 \AA)$ da pasta de cimento quanto nos poros dos agregados e na zona de interface; ela pode evaporar facilmente quando a umidade relativa é baixa ou a temperatura ambiente é alta. A água de gel se encontra nos nanoporos $(15 \AA-20 \AA)$ da pasta de cimento e é geralmente descrita como água adsorvida ou fisicamente ligada e não evapora facilmente, porém pode ser perdida quando a temperatura ambiente for elevada. A água quimicamente combinada, também conhecida como água não-evaporável, é parte dos hidratos do cimento e apenas pode ser liberada quando a decomposição química da pasta de cimento e dos agregados ocorre sob elevadas temperaturas (acima de $500{ }^{\circ} \mathrm{C}$ ). Estes três tipos de água são conhecidos como macro-, meso- e micro-água, respectivamente [23].

A maneira mais simples para avaliar a mudança de umidade no concreto é pelo monitoramento da perda de massa que, sob temperaturas elevadas, é significativamente dependente da composição química dos constituintes e dos regimes de aquecimento. Em geral, a perda de massa do concreto aumenta com o aumento da temperatura máxima de exposição seguindo três estágios característicos. No primeiro estágio (até $200{ }^{\circ} \mathrm{C}$ ), a perda de massa aumenta muito rapidamente com a temperatura e é atribuída à evaporação da água dos capilares, sendo, portanto, um processo predominantemente físico. Quando a temperatura máxima de exposição varia entre $200{ }^{\circ} \mathrm{C}$ e $400{ }^{\circ} \mathrm{C}$, a perda de massa é promovida principalmente pela evaporação da água do gel de C-S-H, com uma taxa de evaporação bastante reduzida já que a saída de água dos poros intermediários é difícil, o que caracteriza este segundo estágio como um processo físico-químico. No terceiro estágio (acima de $400{ }^{\circ} \mathrm{C}$ ), a perda de massa é promovida principalmente pela decomposição da pasta de cimento e dos agregados, representando um processo predominantemente químico devido à evaporação da água quimicamente combinada [12, 23]. A relação entre os tipos de água presentes no concreto, seus materiais constituintes e a temperatura é apresentada na Fig. 2.

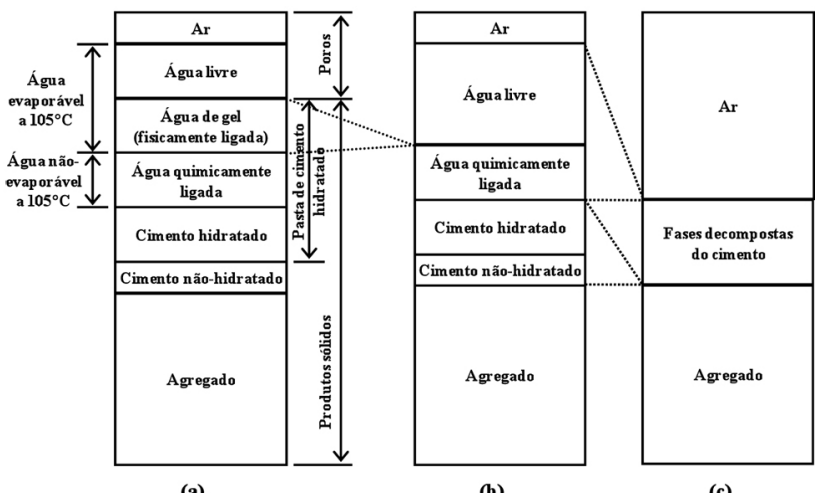

(a)

(b)

(c)

Figura 2: Tipos de água no concreto relacionados com seus constituintes e com a temperatura: (a) $20{ }^{\circ} \mathrm{C}$, (b) $105{ }^{\circ} \mathrm{C}$ e (c) $850{ }^{\circ} \mathrm{C}$ [24].

[Figure 2: Types of water in the concrete related to its constituents and temperature: (a) $20^{\circ} \mathrm{C}$, (b) $105^{\circ} \mathrm{C}$ and (c) $\left.850{ }^{\circ} \mathrm{C}[24].\right]$

Há uma relação direta entre o tempo de exposição e a perda de massa nos três estágios da evaporação da umidade. Na primeira hora, a taxa de evaporação é reduzida já que o calor só remove a umidade próxima à superfície da amostra. Entre as $10 \mathrm{~h}$ e $24 \mathrm{~h}$ seguintes, a umidade diminui acentuadamente, de maneira que a perda de massa é alta. 
A temperatura também se torna gradualmente uniforme na amostra e expulsa a umidade no interior da amostra de concreto. Depois desse período, a taxa de evaporação é novamente reduzida e a perda de umidade tende a se estabilizar. Para temperaturas inferiores, o tempo de exposição para que a migração da umidade estabilize é mais longo, enquanto um tempo de exposição de 12 h é suficiente para a estabilização da umidade sob temperaturas maiores (acima de $500{ }^{\circ} \mathrm{C}$ ) [12]. Assim, o tempo de exposição e o período de cura também influenciam a resistência de concretos expostos às altas temperaturas. Tempos de exposição prolongados aumentam levemente a resistência para temperaturas de aquecimento menores, mas reduzem significativamente a resistência sob temperaturas maiores. Um período de cura prolongado sempre contribui para o aumento da resistência, porém esse efeito fortalecedor se torna insignificante após 28 dias [12].

Uma questão importante no desenvolvimento de um estudo sobre o comportamento de concretos expostos a altas temperaturas é o papel do procedimento de ensaio. Não existe uma norma consensual sobre a medida das propriedades sob tais condições e os diversos pesquisadores do assunto têm utilizado métodos distintos. Assim, é necessário compreender se o procedimento de ensaio tem efeitos significativos sobre as relações medidas entre a temperatura e as propriedades do concreto [18]. Existem três variações para o ensaio sob altas temperaturas no estado estacionário, os quais são comumente conhecidos como ensaios tensionados, não-tensionados e de tensão residual não-tensionado. Cada um destes métodos fornece resultados típicos das condições de tensão interna nos específicos elementos de concreto [17]: ensaios tensionados: são mais adequados para representar o desempenho do concreto de um pilar ou da região comprimida da viga, pois neste ensaio um pré-carregamento - normalmente correspondendo entre $20 \%$ e $40 \%$ da resistência à compressão final medida na temperatura ambiente - é aplicado na amostra de concreto antes do aquecimento e mantido durante o ensaio. $\mathrm{O}$ calor é aplicado sob uma taxa constante até atingir a temperatura desejada e mantido até que um estado estacionário térmico seja alcançado. Então, a carga ou a deformação é aumentada de acordo com a taxa predeterminada até a ruptura da amostra; ensaios não-tensionados: são mais adequados para representar o desempenho do concreto da região tracionada da viga ou de um elemento pouco solicitado à compressão, pois neste ensaio a amostra é aquecida sem pré-carregamento a uma taxa constante até a temperatura alvo, e mantida até atingir um estado estacionário térmico. Então, a carga ou a deformação é aumentada de acordo com a taxa predeterminada até a ruptura da amostra; tensão residual não-tensionado: é adequado para avaliar as propriedades pós-fogo (ou residuais) do concreto, pois neste ensaio a amostra é aquecida sem pré-carregamento a uma taxa constante até a temperatura alvo e mantida até que um estado estacionário térmico seja atingido. Então, a amostra é resfriada - também de acordo com uma taxa predeterminada - até a temperatura ambiente. A carga ou a deformação é aplicada até a ruptura da amostra nas condições do ambiente. Dentre os carregamentos térmicos, o choque térmico é o mais severo, pois gradientes de alta temperatura e picos de pressão de vapor ocorrem nos poros. Com isto, tensões de tração superiores à resistência à tração do concreto podem ser geradas, seguido pelo lascamento explosivo do material próximo à superfície aquecida [16].

Também é importante saber quantificar os efeitos de outras variáveis chaves - tais como as proporções da mistura e a incorporação de sílica ativa - sobre as propriedades de concretos de alta resistência sob altas temperaturas [18]. Os concretos incorporados com sílica ativa são mais sensíveis às altas temperaturas, sendo altamente propensos à fissuração e ao lascamento, apresentando um desempenho inferior aos concretos convencionais (sem adição mineral) após o aquecimento. A maior perda de resistência observada para os concretos incorporados com sílica ativa é associada ao teor de sílica, que produz uma zona de interface mais densa entre os agregados e a matriz devido ao efeito filler e à reação pozolânica promovidos por suas pequenas partículas. Quando expostos às altas temperaturas, a pasta de cimento retrai enquanto os agregados expandem, enfraquecendo a zona de interface e a ligação entre eles; como consequiência, este processo aliado à decomposição química dos produtos hidratados promovem uma severa deterioração e perda de resistência no concreto submetido a tais condições. A dosagem de sílica não tem nenhum efeito significativo sobre a resistência à compressão residual de concretos aquecidos até $200{ }^{\circ} \mathrm{C}$, porém a quantidade desta adição mineral passa a influenciar o comportamento mecânico residual dos concretos submetidos a temperaturas superiores a $300{ }^{\circ} \mathrm{C}$; geralmente uma substituição de $10 \%$ em peso de cimento é considerada um limite para evitar o lascamento [3,25].

Com a crescente utilização do concreto de alta resistência em aplicações estruturais, as diferenças comportamentais observadas entre este e o concreto convencional e a inaplicabilidade das normas existentes para concretos expostos ao fogo devem ser reconhecidas a fim de reduzir a probabilidade de uma ruptura prematura em uma situação de incêndio. Até o momento, a quantidade de dados de ensaio de concretos de alta resistência expostos ao fogo disponível é insuficiente para as diversas variáveis a serem consideradas (resistência, permeabilidade e porosidade do concreto, tipo de agregado, taxa de aquecimento etc.), com destaque para os resultados obtidos a partir do ensaio tensionado que simula a condição do elemento estrutural no caso de incêndio. Além disso, a variação das relações tensão-deformação do concreto de alta resistência com a temperatura deve ser estabelecida experimentalmente e, apesar de não serem amplamente publicadas na literatura, são essenciais para o desenvolvimento de modelos constitutivos para predeterminar o desempenho estrutural de concretos de alta resistência durante um incêndio [17].

\section{Utilização de fibras de polipropileno}

O lascamento resulta de dois processos concomitantes: o processo termo-mecânico, associado com os gradientes de dilataçãoou retração térmicosqueocorrem dentro doelemento exposto a altas temperaturas; e o processo termo-hídrico, 
relacionado com a transferência de massa na rede de poros (ar, vapor e água líquida) e que resulta no desenvolvimento de altas pressões. Assim, o lascamento do concreto ocorre por um processo termo-hidro-mecânico [24, 26-30]. O processo termo-mecânico está associado diretamente com o gradiente de temperatura no elemento de concreto, que induz a tensões de compressão próximas a superfície aquecida e a tensões de tração nas regiões internas do corpo. Além disso, existem as incompatibilidades de deformação entre a pasta de cimento e os agregados: enquanto os agregados dilatam com o aumento da temperatura, a pasta de cimento retrai devido à perda de água por secagem ou desidratação e pela degradação química, que começa principalmente a partir de $180{ }^{\circ} \mathrm{C}[24,26]$. O processo termo-hídrico está associado com a transferência de massa (água líquida, vapor d'água e ar). À medida que a temperatura aumenta, a água é parcialmente evaporada, gerando uma pressão na rede de poros. A baixa difusividade térmica do concreto resulta em um acentuado gradiente de temperatura próximo a superfície aquecida, fazendo com que o fluxo de umidade ocorra tanto para fora quanto para dentro do elemento. $O$ vapor d'água e o ar são parcialmente direcionados para a superfície aquecida, mas eles também migram para o centro do elemento onde o vapor condensa novamente assim que as condições termodinâmicas são satisfeitas, resultando em uma camada quase-saturada. Depois de algum tempo, o elemento de concreto contém, a partir da superfície aquecida: a) uma região seca e desidratada, b) uma região em processo de secagem e desidratação e c) uma camada quase-saturada que atua como uma parede impermeável, enquanto o restante do elemento estrutural não é alterado. Assim, quanto menor a permeabilidade do material, mais rápido - e mais próximo à superfície aquecida - o obstáculo de umidade (camada quase-saturada) é gerado e maior a pressão e o seu gradiente resultantes [24, 26]. A migração da umidade é determinada pelos gradientes de temperatura, pressão nos poros e concentração de umidade [24]. A consideração de um gradiente de temperatura dentro da amostra é uma função das propriedades térmicas do material e das mudanças físico-químicas que ocorrem durante o aquecimento. O desenvolvimento de um gradiente de pressão, associado às transferências de massa e de energia, atinge um máximo com o tempo, comprovando a progressão da frente de secagemdesidratação para o interior da amostra. Este gradiente também é controlado pela permeabilidade do concreto ao gás e ao líquido. Como uma consequiência direta do aumento da temperatura, a perda de massa é associada principalmente à perda de água, eliminada no estado de vapor, cuja cinética é controlada principalmente pela permeabilidade do concreto localizado entre a superfície aquecida e a frente de secagem-desidratação [27]. De acordo com Sullivan [31], existem dois tipos de lascamento: o normal (progressivo) e o explosivo, cujos mecanismos são completamente distintos. O lascamento normal acontece quando a resistência à tração do concreto é alcançada na superfície da amostra durante o aquecimento, promovendo a fissuração e, conseqüentemente, o desprendimento de material. Este é um tipo de ruptura dúctil, já que aparecem fissuras prévias na superfície da amostra. Por outro lado, o lascamento explosivo é uma ruptura frágil e que ocorre repentina e violentamente. Este é promovido pelas tensões e deformações impostas à estrutura do gel de C-S-H, desenvolvendo elevadas energias dentro da estrutura. Estas tensões não são necessariamente de tração, podendo ser também de compressão ou uma combinação de ambas, já que a restrição ao movimento de um elemento pode aumentar a probabilidade do lascamento explosivo. Devido à elevada perda de massa de concreto durante a ação do fogo, o lascamento expõe as camadas mais internas às altas temperaturas, aumentando a taxa de transmissão de calor para o interior do elemento e para a armadura. Assim, a integridade e a capacidade portante da estrutura de concreto podem ser prejudicadas, as armaduras de reforço podem ser expostas diretamente ao fogo e a estrutura inteira fica comprometida (ruptura). A cinética e a amplitude do processo de lascamento são controladas pelas propriedades dos materiais, assim como pelas características do elemento estrutural e das solicitações térmicas e mecânicas. As propriedades dos materiais incluem as propriedades de transferência de calor e de massa (condutividade e capacidade térmica, permeabilidade ao vapor e à água líquida) e mecânicas (resistência, fluência térmica etc.), as quais evoluem significativamente durante a solicitação do elemento devido às mudanças na microestrutura (porosidade, distribuição granulométrica dos poros, microfissuração) e dependem do teor de umidade e da dilatação térmica dos agregados. Em uma escala maior, o tamanho e a forma do elemento estrutural também determinam os gradientes de temperatura e de umidade e, dessa maneira, toda a história termo-hidro-mecânica. Assim, o lascamento é um processo cuja complexidade é originada pelo conjunto dos processos térmicos, hídricos, químicos e mecânicos, além das leis que os governam [4, 20, 26]. De acordo com Phan e Carino [18], a temperatura no centro de uma amostra de concreto, quando o lascamento explosivo é observado, varia entre $200{ }^{\circ} \mathrm{C}$ e $325^{\circ} \mathrm{C}$ e o tempo do lascamento coincide com o tempo no qual existe uma grande diferença de temperatura entre a superfície e o centro da amostra. Assim, enquanto a pressão nos poros pode ser a causa principal do lascamento explosivo, a presença de tensões induzidas termicamente pode ter um efeito secundário (mas significativo) sobre este tipo de ruptura do material [21]. É importante destacar que é possível verificar variações para a faixa de temperatura na qual ocorre o lascamento, sendo ela definida de acordo com os fatores que influenciam o fenômeno, ou seja, a estrutura de poros do concreto, o teor de umidade, a taxa de aquecimento, a configuração da amostra etc. [5]. A possibilidade da ocorrência do lascamento é maior com a redução da relação água/cimento ou com a densificação adicional da matriz pela incorporação de adições minerais, além das tensões entre o agregado e a pasta de cimento que são geradas em função de suas incompatibilidades térmicas [1]. Normalmente, a combinação de baixa permeabilidade, baixa porosidade, baixa condutividade térmica e alto teor de umidade leva ao aumento da tendência ao lascamento [10]. 
O lascamento explosivo acontece nos primeiros estágios de um incêndio sob a ação combinada da pressão nos poros e das tensões térmicas. As fissuras se desenvolvem paralelas à superfície quando a soma das tensões excede a resistência de tração do material. Isto é acompanhado pela liberação repentina de energia e uma violenta ruptura da região aquecida (Fig. 3) [24].

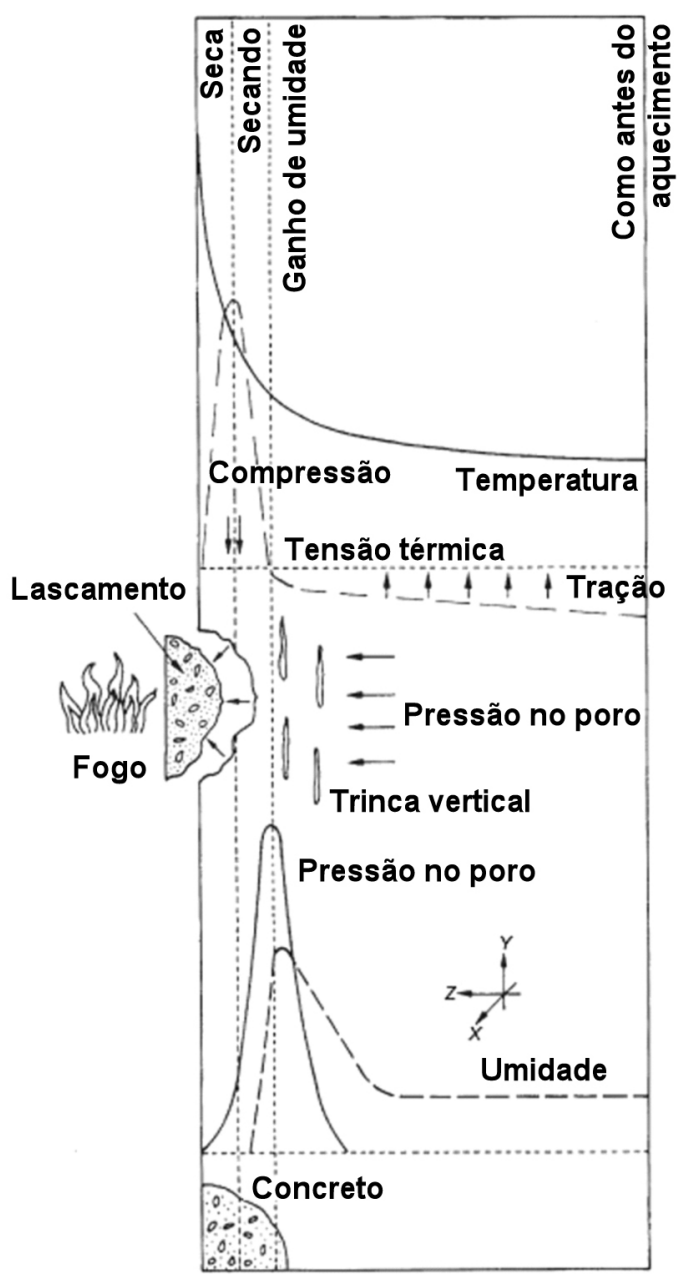

Figura 3: Lascamento devido à combinação dos mecanismos de pressão nos poros e tensões térmicas [24].

[Figure 3: Spalling due to the combination of pore pressure and thermal stress mechanisms [24].]

O lascamento em elementos de concreto convencional pode ser evitado pela correta seleção das dimensões, da forma da seção transversal, da distribuição das tensões mecânicas e do arranjo da armadura, em conjunto com sua secagem. Porém, a experiência prática e os ensaios dos materiais mostram que o lascamento de elementos de concreto de alta resistência sempre ocorre quando há exposição ao fogo, mesmo para baixas taxas de aquecimento. A principal razão para isso é que a matriz densa destes concretos (com permeabilidade extremamente baixa) impede a saída do vapor d'água gerado com as altas temperaturas. Com isto, pressões de vapor são geradas dentro dos poros da matriz, que aumentam com o aquecimento; as pressões geradas nos poros continuam a aumentar até que estas promovem o lascamento explosivo do concreto aquecido [2, 17]. A tendência ao lascamento explosivo de concretos de alta resistência indica que elementos estruturais produzidos com estes materiais podem ser mais susceptíveis à perda do cobrimento que fornece proteção térmica à armadura [18]. Isto pode ser evitado pela introdução de um sistema capilar artificial dentro da massa de concreto destes elementos, o qual pode ser obtido durante ou após o endurecimento do material (sem prejudicar as propriedades inicialmente desejadas) ou sob a influência do fogo. Este procedimento pode ser alcançado com a introdução de fibras de baixo ponto de fusão que formam capilares por meio da dissolução, amolecimento, decomposição, retração ou fusão, cujos benefícios podem ser maximizados pela forma (diâmetro e comprimento) das fibras e quantidade incorporada [4, 10]. Devido à quantidade de fatores envolvidos, as fibras podem ser corretamente distribuídas por toda a matriz do concreto, ao redor das partículas de agregados e ainda nas camadas de contorno dos elementos [32]. Por possuírem um baixo módulo de elasticidade, as fibras de polipropileno não evitam a formação e a propagação de trincas sob altos níveis de tensões [32]. Porém, sua utilização em concreto reduz consideravelmente a ocorrência de lascamento no material quando exposto ao fogo, sendo este efeito função da densidade da matriz (relação água/cimento), da umidade inicial das amostras, do tipo e da quantidade de agregado e do tipo, espessura e comprimento das fibras e da taxa de aquecimento adotada $[1,14,15,33]$. Como as fibras de polipropileno fundem próximo a $170{ }^{\circ} \mathrm{C}$, elas têm um efeito significativo sobre o comportamento hidráulico do concreto sob altas temperaturas, ou seja, nesta temperatura inicia-se a formação de uma rede permeável que permite a migração dos gases para o exterior, reduzindo a pressão nos poros do material e, conseqüentemente, eliminando a possibilidade de ocorrência do lascamento explosivo nos concretos de alta resistência [10, 22, 27, 28].

A permeabilidade do concreto é determinada por sua microestrutura e/ou porosidade e é esta propriedade que controla a expulsão de água do material submetido a temperaturas variadas. Dessa maneira, a estrutura de poros e o teor de aglomerante têm um efeito considerável sobre o comportamento de concretos expostos ao fogo, especialmente sobre o lascamento observado sob altas temperaturas. Como a incorporação de fibras altera a microestrutura de um concreto, as propriedades inerentes dos diferentes tipos de fibras também influenciam as propriedades destes materiais sob ação do fogo [10, 34]. Os efeitos da fusão e da degradação das fibras contribuem para o aumento do volume de poros. Como a espessura da fibra corresponde à espessura da zona de interface, a utilização destas aparentemente introduz uma zona de interface adicional, resultando em uma maior permeabilidade do concreto [29]. Assim, para que as fibras de polipropileno contribuam com o aumento da permeabilidade quando fundidas, dois critérios devem ser obedecidos: pelo menos uma parte das fibras deve ser 
absorvida pela matriz cimentícia circundante; e as fibras devem constituir uma rede conectada, seja sozinha ou em conjunto com outros vazios mais permeáveis que a matriz [27].

Os mecanismos potenciais para o alívio da pressão nos poros de concretos aquecidos induzidos pela presença de fibras de polipropileno podem ser de duas formas: os reservatórios descontínuos (bolhas de ar e microfissuras) para acomodar o vapor em expansão e os canais contínuos para a migração do vapor de umidade. A eficiência dos mecanismos de alívio de pressão não depende apenas das características do material polipropileno, mas também das características da própria fibra relacionadas com suas dimensões. Considerações importantes incluem a utilização de monofilamentos lisos de pequenos diâmetros e comprimento adequado para permitir uma boa dispersão das fibras e a interconectividade entre elas. Os parâmetros que podem ser significantes para a criação de reservatórios e canais contínuos são a área superficial gerada e o comprimento linear adicional obtido, os quais dependem do teor de fibra [24].

Como as fibras de polipropileno possuem uma superfície hidrofóbica e um módulo de elasticidade menor que a matriz de cimento, a existência de uma adesão físico-química entre a fibra e a matriz é normalmente descartada [35]. Para superar essa dificuldade, fibras de polipropileno especiais estão sendo desenvolvidas para a utilização em materiais à base de cimento, onde dois mecanismos contribuem com a ligação: a adesão interfacial e o ancoramento mecânico. Os efeitos da adesão são mais importantes para o aumento da resistência ao início da fissuração, enquanto o ancoramento mecânico tem maior importância para a zona pós-fissuração, pois a ligação fibra-matriz deve permanecer efetiva para grandes deslocamentos à medida que a fibra é sacada da matriz [36]. As fibras de polipropileno sofrem mudanças de fases diretas à medida que são aquecidas, iniciando com a fase de transição vítrea (amolecimento), seguida pela fase de fusão endotérmica que inicia a $150{ }^{\circ} \mathrm{C}$, atinge o pico a $165{ }^{\circ} \mathrm{C}$ e se completa a $176{ }^{\circ} \mathrm{C}$. Na fusão, uma fibra contrai no comprimento e expande na largura, resultando em um aumento de volume total de $7 \%$. A fusão é seguida por uma pirólise endotérmica envolvendo a quebra da cadeia principal de carbono em moléculas menores. A pirólise detectável começa aproximadamente a $325{ }^{\circ} \mathrm{C}$ com a liberação de vapores de hidrocarbonetos, atinge o pico próximo a 460 ${ }^{\circ} \mathrm{C}$ e completa a $475{ }^{\circ} \mathrm{C}$. Os produtos voláteis entram em combustão a $550{ }^{\circ} \mathrm{C}$ na presença de oxigênio, mas quando expostos diretamente a chama, a combustão acontece entre $350{ }^{\circ} \mathrm{C}$ e $400{ }^{\circ} \mathrm{C}$. Durante um incêndio, a combustão acontece preferencialmente para vapores de hidrocarbonetos liberados a partir da superfície do concreto [30]. Assim, as transformações das fibras de polipropileno no concreto aquecido ocorrem dentro de um ambiente físico, químico, térmico, hídrico e mecanicamente complexo. A presença das fibras de polipropileno influencia preferencialmente a distribuição de umidade e a pressão nos poros dentro do concreto tanto no espaço quanto no tempo. Os gradientes de temperatura também são influenciados pelo transporte de energia promovido pela migração de umidade e pelas reações de calor das fibras [24]. As propriedades típicas de uma fibra de polipropileno incluem: densidade de $0,90 \mathrm{~g} / \mathrm{cm}^{3}$, resistência à tração entre $550 \mathrm{MPa}$ e $690 \mathrm{MPa}$, módulo de elasticidade de 3,40 GPa e alongamento no escoamento de 15\% [9]. Quimicamente, esta fibra apresenta uma boa resistência aos ácidos e aos álcalis, porém é susceptível à oxidação (por isto as fibras comercializadas são estabilizadas contra essa reação) [30]. Do ponto de vista industrial, uma dosagem de fibra de $2 \mathrm{~kg} / \mathrm{m}^{3}$ de concreto, com comprimento entre $10 \mathrm{~mm}$ e $20 \mathrm{~mm}$ e diâmetro entre $50 \mu \mathrm{m}$ e $200 \mu \mathrm{m}$ normalmente é adotada como regra para evitar o lascamento em concretos de alta resistência. Porém, estes valores não são otimizados e não podem ser extrapolados para uma ampla variação de concreto - com maior resistência, menor permeabilidade ou partículas menores - sem se conhecer exatamente como a fibra atua, em particular quando ela própria não constitui uma rede interconectada [27]. Os resultados de ensaios desenvolvidos por diversos pesquisadores e apresentados na literatura indicam efeitos contraditórios da adição de fibra de polipropileno sobre as resistências à compressão e à tração do concreto, sendo essas diferenças atribuídas às variações na composição da matriz, no tipo e na quantidade de fibra adicionada, nas condições de produção do material e nos métodos de ensaio adotados [37]. A incorporação de fibra de polipropileno não resulta necessariamente em uma redução significativa da resistência, mesmo que ela vaporize sob altas temperaturas [11]; porém verifica-se que a resistência final de concretos incorporados com essas fibras mostra uma redução bem definida em função da temperatura máxima de exposição. Isso pode ser explicado pelos vazios criados durante a fusão da fibra, que resultam em um material com baixa resistência. Isto ocorre pela conversão dos vazios ocupados pelas fibras em microfissuras que podem causar a ruptura prematura sob tensões de tração e pela dispersão insuficiente das fibras durante o processo de mistura, criando uma estrutura de múltiplos filamentos no concreto que aumentam a porosidade local e, assim, a resistência diminui $[9,15]$. A incorporação de fibras de polipropileno não implica no aumento da tenacidade do concreto quando comparado com os valores obtidos para concreto sem fibras após exposição a $600{ }^{\circ} \mathrm{C}$, porém, após $800{ }^{\circ} \mathrm{C}$, valores menores são obtidos para estes concretos quando comparado às misturas sem fibras. Isto indica que as fibras de polipropileno contribuem pouco com a capacidade de absorção de energia dos concretos após exposição às altas temperaturas, embora elas melhorem levemente a tenacidade dos concretos sem aquecimento. Enquanto a perda de dureza do concreto é muito mais rápida após exposição às altas temperaturas, a perda de tenacidade é mais lenta quando comparada com a perda de resistência à compressão [15]. Além disso, verifica-se uma diferença significativa entre a porosidade de concretos com e sem a incorporação de fibras de polipropileno após exposição a temperaturas superiores a $200{ }^{\circ} \mathrm{C}$, o que pode resultar em uma menor pressão de vapor nos primeiros instantes da exposição ao calor, indicando um 
menor risco ao lascamento no caso de um incêndio acidental [10]. Assim, além do efeito positivo sobre o lascamento de concretos expostos às altas temperaturas, as fibras de polipropileno reduzem a trabalhabilidade e a exsudação de água para a superfície do concreto, evitando a segregação quando no estado fresco e aumentam a resistência à tração, a capacidade de deformação na tração e a resistência ao gelodegelo do concreto quando no estado endurecido. Com isto, nos últimos anos, as fibras de polipropileno têm ganhado popularidade e têm sido adicionadas em pequenas frações à mistura de concreto para reduzir a fissuração por retração (plástica e por secagem) [9, 30].

\section{CONCLUSÕES}

Apesar de o concreto ser considerado resistente à ação do fogo, verifica-se que, na prática, o desempenho deste material é prejudicado pelas altas temperaturas. Além disso, os comportamentos do concreto convencional e do concreto de alta resistência sob altas temperaturas são distintos. Os concretos de alta resistência apresentam uma maior sensibilidade às altas temperaturas devido à sua porosidade reduzida, sendo as duas diferenças principais relacionadas com a perda relativa das propriedades mecânicas (resistência à compressão e módulo de elasticidade) e com a ocorrência do lascamento explosivo na faixa de temperatura entre $100{ }^{\circ} \mathrm{C}$ e $400{ }^{\circ} \mathrm{C}$. Com isso surgem dúvidas sobre a aplicabilidade das normas existentes para o projeto de estruturas de concretos de alta resistência expostas à ação do fogo, uma vez que elas são amplamente baseadas no comportamento de concretos convencionais. Assim, dada a crescente utilização dos concretos de alta resistência, as diferenças de comportamento observadas entre os concretos e a inaplicabilidade das normas existentes para o projeto de estruturas de concretos de alta resistência expostas à ação do fogo, estudos contínuos devem ser efetuados sobre o comportamento destes materiais expostos às altas temperaturas a fim de se evitar uma grande probabilidade de colapso em situação real de incêndio.

\section{REFERÊNCIAS}

[1] D. Matesová, D. Bonen, S. P. Shah, Factors affecting the resistance of cementitious materials at high temperatures and medium heating rates, Materials and Structures 39, 9 (2006) 919-935.

[2] S. Y. N. Chan, G. F. Peng, J. K. W. Chan, Comparison between high strength concrete and normal strength concrete subjected to high temperature, Materials and Structures 29, 10 (1996) 616-619.

[3] C.-S. Poon, S. Azhar, M. Anson, Y.-L. Wong, Comparison of the strength and durability performance of normal-and high-strength pozzolanic concretes at elevated temperatures, Cement Concrete Res. 31, 9 (2001) 1291-1300.

[4] V. K. R. Kodur, T. C. Wang, F. P. Cheng, Predicting the fire resistance behavior of high strength concrete columns, Cement Concrete Composites 26, 2 (2004) 141-153.
[5] Y. N. Chan, G. F. Peng, M. Anson, Residual strength and pore structure of high-strength concrete and normal strength concrete after exposure to high temperatures, Cement Concrete Composites 21, 1 (1999) 23-27.

[6] S. K. Handoo, S. Agarwal, S. K. Agarwal, Physicochemical, mineralogical, and morphological characteristics of concrete exposed to elevated temperatures, Cement Concrete Res. 32, 7 (2002) 1009-1018.

[7] C.-H. Chiang, C.-C. Yang, Artificial neural networks in prediction of concrete strength reduction due to high temperature, ACI Mater. J. 102, 2 (2005) 93-102.

[8] Y. F. Chang, Y. H. Chen, M. S. Sheu, G. C. Yao, Residual stress-strain relationship for concrete after exposure to high temperatures, Cement Concrete Res. 36, 10 (2006) 19992005.

[9] Z. Bayasi, M. Al Dhaheri, Effect of exposure to elevated temperature on polypropylene fiber-reinforced concrete, ACI Mater. J. 99, 1 (2002) 22-26.

[10]A. Noumowe, Mechanical properties and microstructure of high strength concrete containing polypropylene fibers exposed to temperatures up to $200{ }^{\circ} \mathrm{C}$, Cement Concrete Res. 35, 11 (2005) 2192-2198.

[11] Y. N. Chan, X. Luo, W. Sun, Compressive strength and pore structure of high-performance concrete after exposure to high temperature up to $800^{\circ} \mathrm{C}$, Cement Concrete Res. 30, 2 (2000) 247-251.

[12] B. Zhang, N. Bicanic, Residual fracture toughness of normal- and high-strength gravel concrete after heating to $600{ }^{\circ} \mathrm{C}$, ACI Mater. J. 99, 3 (2002) 217-226.

[13] M. Li, C. X. Qian, W. Sun, Mechanical properties of high-strength concrete after fire, Cement Concrete Res. 34, 6 (2006) 1001-1005.

[14] K. D. Hertz, Limits of spalling of fire-exposed concrete, Fire Safety J. 38, 2 (2003) 103-116.

[15] C. S. Poon, Z. H. Shui, L. Lam, Compressive behavior of fiber reinforced high-performance concrete subjected to elevated temperatures, Cement Concrete Res. 34, 12 (2004) 2215-2222.

[16] B. Wu, X.-P. Su, H. Li, J. Yuan, Effect of high temperature on residual mechanical properties of confined and unconfined high-strength concrete, ACI Mater. J. 99, 4 (2002) 399-407.

[17] L. T. Phan, N. J. Carino, Review of mechanical properties of HSC at elevated temperature, J. Mater. Civil Eng. 10, 1 (1998) 58-64.

[18] L. T. Phan, N. J. Carino, Effects of test conditions and mixture proportions on behavior of high-strength concrete exposed to high temperatures, ACI Mater. J. 99, 1 (2002) 54-56.

[19] L. T. Phan, N. J. Carino, Code provisions for high strength concrete: strength-temperature relationship at elevated temperatures, Materials and Structures 36, 2 (2003) 91-98.

[20] X. Luo, W. Sun, S. Y. N. Chan, Effect of heating and cooling regimes on residual strength and microstructure of normal strength and high performance concrete, Cement Concrete Res. 30, 3 (2000) 379-383. 
[21] L. T. Phan, J. R. Lawson, F. L. Davis, Effects of elevated temperature on heating characteristics, spalling, and residual properties of high performance concrete, Materials and Structures 34, 2 (2001) 83-91.

[22] G.-F. Peng, W.-W. Yang, J. Zhao, Y.-F. Liu, S.-H. Bian, L.-H. Zhao, Explosive spalling and residual mechanical properties of fiber-toughened high-performance concrete subjected to high temperatures, Cement Concrete Res. 36, 4 (2006) 723-727.

[23] B. Zhang, N. Bicanic, C. J. Pearce, D. V. Phillips, Relationship between brittleness and moisture loss of concrete exposed to high temperatures, Cement Concrete Res. 32, 3 (2002) 363-371.

[24] G. A. Khoury, Polypropylene fibers in heated concrete. Part 2: pressure relief mechanisms and modeling criteria, Magazine Concrete Res. 60, 3 (2008) 189-204.

[25] A. Behnood, H. Ziari, Effects of silica fume addition and water to cement ratio on the properties of high-strength concrete after exposure to high temperatures, Cement Concrete Composites 30, 2 (2008) 106-112.

[26] P. Kalifa, F.-D. Menneteau, D. Quenard, Spalling and pore pressure in HPC at high temperatures, Cement Concrete Res. 30, 12 (2000) 1915-1927.

[27] P. Kalifa, G. Chéné, C. Gallé, High-temperature behavior of HPC with polypropylene fibers: from spalling to microstructure, Cement Concrete Res. 31, 10 (2001) 14871499.

[28] B. Chen, J. Liu, Residual strength of hybrid-fiberreinforced high-strength concrete after exposure to high temperatures, Cement Concrete Res. 34, 6 (2004) 10651069.

[29] M. Zeiml, D. Leithner, R. Lackner, H. A. Mang, How do polypropylene fibers improve the spalling behavior of insitu concrete?, Cement Concrete Res. 36, 5 (2006) 929-942. [30] G. A. Khoury, B. Willoughby, Polypropylene fibers in heated concrete. Part 1: molecular structure and materials behavior, Magazine Concrete Res. 60, 2 (2008) 125-136.

[31] P. J. E. Sullivan, A probabilistic method of testing for the assessment of deterioration and explosive spalling of high strength concrete beams in flexure at high temperature, Cement Concrete Composites 26, 2 (2004) 155-162.

[32] C. X. Qian, P. Stroeven, Development of hybrid polypropylene-steel fiber-reinforced concrete, Cement Concrete Res. 30, 1 (2000) 63-69.

[33] A. Bilodeau, V. K. R. Kodur, G. C. Hoff, Optimization of the type and amount of polypropylene fibers for preventing the spalling of lightweight concrete subjected to hydrocarbon fire, Cement Concrete Composites, 26, 2 (2004) 163-174.

[34] P. Raivio, L. Sarvaranta, Microstructure of fiber mortar composites under fire impact - effect of polypropylene and polyacrylonitrile fibers, Cement Concrete Res. 24, 5 (1994) 896-906.

[35] A. Nanni, N. Meamarian, Distribution and opening of fibrillated polypropylene fibers in concrete, Cement Concrete Composites 13, 2 (1991) 107-114.

[36] A. Peled, H. Guttman, A. Bentur, Treatments of polypropylene fibers to optimize their reinforcing efficiency in cement composites, Cement Concrete Composites 14, 4 (1992) 277-285.

[37] A. M. Alhozaimy, P. Soroushian, F. Mirza, Mechanical properties of polypropylene fiber reinforced concrete and the effects of pozzolanic materials, Cement Concrete Composites 18, 2 (1996) 85-92.

(Rec. 13/12/2008, Ac. 28/03/2009) 